\title{
Kaposi's Sarcoma Associated-Herpes Virus (KSHV) Seroprevalence in Pregnant Women in South Africa
}

Babatyi I Malope-Kgokong ${ }^{1,3}$, Patrick MacPhail ${ }^{1}$, Georgina Mbisa², Edith Ratshikhopha ${ }^{3}$, Mhairi Maskew $^{1}$, Lara Stein ${ }^{3}$, Freddy Sitas ${ }^{4}$, Denise Whitby ${ }^{2^{*}}$

\begin{abstract}
Background: Factors previously associated with Kaposi's sarcoma-associated herpesvirus (KSHV) transmission in Africa include sexual, familial, and proximity to river water. We measured the seroprevalence of KSHV in relation to HIV, syphilis, and demographic factors among pregnant women attending public antenatal clinics in the Gauteng province of South Africa.
\end{abstract}

Methods: We tested for antibodies to KSHV lytic K8.1 and latent Orf73 antigens in 1740 pregnant women attending antenatal clinics who contributed blood to the "National HIV and Syphilis Sero-Prevalence Survey - South Africa, 2001". Information on HIV and syphilis serology, age, education, residential area, gravidity, and parity was anonymously linked to evaluate risk factors for KSHV seropositivity. Clinics were grouped by municipality regions and their proximity to the two main river catchments defined.

Results: KSHV seropositivity (reactive to either lytic K8.1 and latent Orf73) was nearly twice that of HIV (44.6\% vs. 23.1\%). HIV and syphilis seropositivity was $12.7 \%$ and $14.9 \%$ in women without KSHV, and $36.1 \%$ and $19.9 \%$ respectively in those with KSHV. Women who are KSHV seropositive were 4 times more likely to be HIV positive than those who were KSHV seronegative (AOR 4.1 95\%Cl: 3.4 - 5.7). Although, women with HIV infection were more likely to be syphilis seropositive (AOR 1.8 95\%Cl: 1.3 - 2.4), no association between KSHV and syphilis seropositivity was observed. Those with higher levels of education had lower levels of KSHV seropositivity compared to those with lower education levels. KSHV seropositivity showed a heterogeneous pattern of prevalence in some localities.

Conclusions: The association between KSHV and HIV seropositivity and a lack of common association with syphilis, suggests that KSHV transmission may involve geographical and cultural factors other than sexual transmission.

\section{Background}

Kaposi Sarcoma-associated herpesvirus (KSHV), also known as Human Herpesvirus 8 (HHV-8) is the causative agent of Kaposi's sarcoma (KS) [1,2], and is associated with primary effusion lymphoma (PEL) [3] and multicentric Castleman's disease [4]. Prevalence of KSHV is elevated in Mediterranean populations [5] and high in sub-Saharan Africa [6-8]. Unlike in the United States and Northern Europe, where KSHV is common

\footnotetext{
* Correspondence: whitbyd@ncifcrf.gov

${ }^{2}$ Viral Oncology Section, AIDS and Cancer Virus Program, SAIC-Frederick, NCIFrederick, Frederick MD, USA

Full list of author information is available at the end of the article
}

mostly in men who have sex with men (MSM), in these endemic regions KS and KSHV affect the general population and it is increasingly apparent that non-sexual modes of transmission play a significant role in the maintenance and spread of KSHV $[9,10]$

The biological, social and environmental factors involved in non-sexual horizontal transmission of KSHV are still largely unknown. The HIV epidemic has had a profound effect on the rate of KS development in Africa. In South Africa, HIV co-infection is associated with up to 50 fold increases in risk for developing KS [11]. The role of HIV as a risk factor for KSHV infection in South Africa is unclear; some reports show a strong association

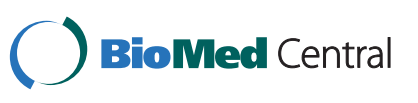


whereas others show none $[9,12]$. Several studies that show a strong association between HIV and KSHV infection fail to show a similar strong association with other sexually transmitted infections that are clearly associated with HIV infection $[9,13]$. Evidence against sexual transmission of KSHV in heterosexual populations continues to emerge [12,14-16]. KSHV infection has been associated with sources of drinking water and with living in close proximity to rivers or streams $[17,18]$. However, the role of vectors and environmental factors in KSHV endemic countries is a topic of ongoing study $[19,20]$.

HIV seroprevalence in pregnant women attending public sector antenatal clinics has been used as a reliable gauge of the South African HIV epidemic [21,22]. Understanding KSHV infection patterns in this group of women will provide a reasonable and comparable estimate of its impact in the same communities. This study aims to examine the seroprevalence of KSHV in pregnant women attending antenatal clinics and to identify the risk for KSHV infection in relation to already collected information on socio-demographic and geographical factors, HIV and syphilis serology.

\section{Materials and methods Study Patients}

This cross sectional study was conducted among 1740 black pregnant women attending public sector antenatal clinics in Gauteng province, South Africa. Women were recruited for the study at their first visit to the clinic during their current pregnancy. The women formed part of a national HIV and sexually transmitted infections (STI) study conducted by the National Department of Health in 2001. A total of 37 clinics within the Gauteng Province formed part of this study. Subjects were then divided into five groups according to the municipalities in which the antenatal clinics were located. These were: East Rand, Soweto, Pretoria, Vaal Triangle and West Rand (Figure 1). Gauteng province is the smallest but second most populated province in South Africa, occupying a total area of $17010 \mathrm{~km}^{2}$. It is mostly urbanized and is home to over 9.6 million people, over a fifth of the national population [23]. The East and West Rand regions are dominated by mining (Figure 1), while the Vaal Triangle contains mainly manufacturing sectors with a mix of agriculture, heavy and petrochemical industries. Tshwane contains light industrial and residential areas, while Soweto is largely residential with residents working mainly in Central Johannesburg and the West Rand. Information on age, education level, parity and gravidity of subjects was collected as part of the original study. Geographic information on river catchments in the areas was deduced from the location of the different clinics. Ethics approval was granted by the University of the Witwatersrand Research Ethics Committee (Medical).

\section{Laboratory Analysis}

Laboratory diagnosis of HIV and syphilis was done by the National Health Laboratory Services (NHLS), South Africa. HIV antibodies were determined using an Abbot Axysm System for HIV-1/HIV-2 ELISA assays (Abbott Laboratories, Diagnostics Division, Abbott Park, Illinois) and syphilis antibodies were determined using a nontreponemal carbon antigen test. Leftover sera were stored at $-20^{\circ} \mathrm{C}$ before being shipped to the Viral Oncology Section, AIDS and Cancer Virus Program, Science Applications International Corporation (SAIC), National Cancer Institute (NCI), Maryland, for determination of antibodies to lytic K8.1 and latent open reading frame (Orf) $73 \mathrm{KSHV}$ antigens. In-house assays for detection of antibodies to lytic K8.1 and latent Orf73 KSHV antigens were used as detailed previously [12,23]. Seropositivity to KSHV was further defined when subjects tested seropositive to either lytic KSHV K8.1 or latent KSHV Orf73 antibodies. Available information on age, education level, parity, gravidity, laboratory HIV and syphilis results was anonymously linked to the KSHV data using unique participant identification numbers.

\section{Statistical Analysis}

Descriptive statistical analysis and measures of effect were done using SAS 9.1 (SAS Institute Inc, Cary, NC, USA.). The Kappa coefficient $(\kappa)$ was calculated to determine concordance between antibodies against the lytic K8.1 and latent Orf73 antigens. Logarithmic transformation of the antibody titres (expressed as optical densities) for lytic K8.1 and latent Orf73 allowed for the use of standard parametric statistical methods and results are expressed as the geometric mean $(\mu \mathrm{g})$ and standard deviation range $(\sigma g)$. Comparisons of means were done using Bonferroni adjusted student $\mathrm{t}$-test between groups or Analysis of Variance (ANOVA) amongst multiple groups. Trends were measured using the Cochran-Armitage Trend Test. We calculated prevalence odds ratios (PORs) and 95\% Wald confidence intervals (CIs) for KSHV seropositivity using logistic regression. In a multivariate model PORs were adjusted for age group ( $\leq 20,21-2526-30, \geq 31)$, education level in years $(<2$ years, $2-5$ years, $6-12$ years and $>12$ years (post matriculation/secondary school) of formal education), municipal region (East Rand, Soweto, Pretoria, Vaal Triangle and West Rand), syphilis seropositivity. Chi-square $(\chi)$ tests for binary measures, trend and homogeneity were calculated and two-sided p-values were used to measure the significance of the associations before and after adjustment for other covariates. 


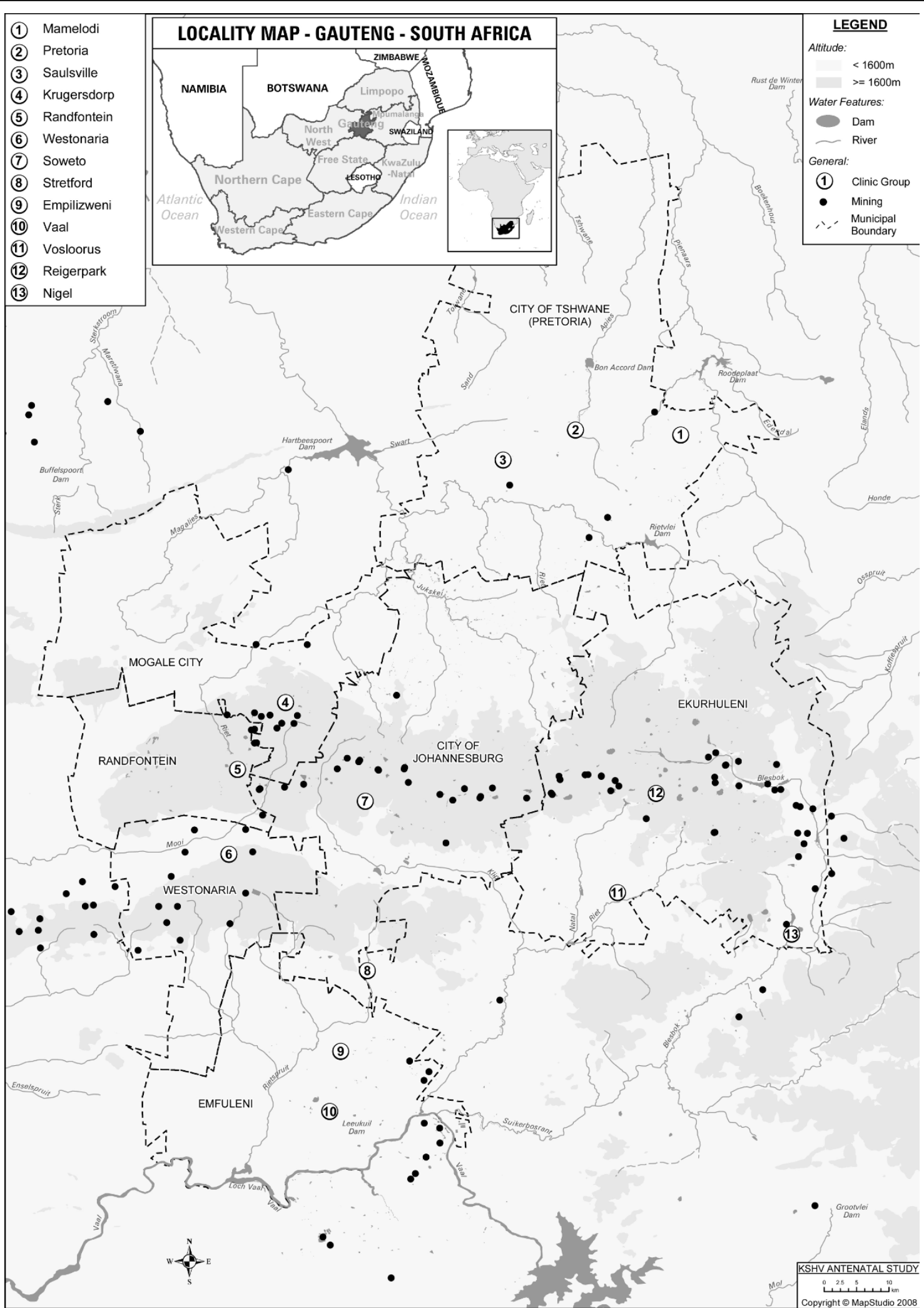

Figure 1 Map of Gauteng province showing the locations of the ante-natal clinics. Locations of ante-natal clinics from which study participants were recruited are shown according to the embedded legend. Altitude, water features and municipal boundaries are also shown according to the embedded legend. 


\section{Results}

The mean $( \pm$ SD) age of all 1740 pregnant women included in the study was $26.0( \pm 6.2)$ years. Age was similar amongst the following four municipal regions: Ekurhuleni $(26.5( \pm 6.3))$, Tshwane $(25.8( \pm 6.1))$, West Rand (26.4 ( \pm 6.1)) and Emfuleni (25.9 ( \pm 6.3)) (Table 1). However, pregnant women attending clinics in Soweto $(24.9( \pm 5.8))$, were significantly younger than those from the West Rand and Ekurhuleni municipalities ( $\mathrm{p}=0.043)$.

\section{Lytic and latent KSHV Serology}

One third (568) of all the subjects were seropositive to lytic K8.1 antibodies and another overlapping third (568) were seropositive to latent Orf73 antibodies (Table 1). Overall, 776 (44.6\%) subjects had antibodies to either lytic K8.1 only (208), latent Orf73 only (208) or both (360) and were considered to be KSHV seropositive. There was moderate concordance in seropositivity between the two (K8.1 and Orf73) assays ( $\kappa=$ 0.46 95\% CI: $0.41-0.50)$ consistent with previous studies[12,24].
The geometric mean $\left(\mu_{\mathrm{g}}\right)$ of optical density for lytic K8.1 was $0.77\left(\left(\sigma_{\mathrm{g}} 0.31\right.\right.$ - 1.38$)$. The mean lytic K8.1 antibody level, expressed as optical densities, were significantly heterogeneous between municipal regions $\left(P_{4 d f}=\right.$ $0.0069)$ and education levels $\left(P_{4 d f}=0.0019\right)$ (Table 1$)$. Women in Tshwane and Soweto had lower lytic K8.1 optical densities than those from the West Rand $\left(\mu_{\mathrm{g}}\right.$ $\left(\sigma_{\mathrm{g}}\right): 0.71(0.32-1.21)$ and $0.71(0.27-1.29)$, vs. $0.84(0.37$ $1.49)$, respectively $\left.\left(P_{4 d f}=0.0069\right)\right]$. The $\mu_{\mathrm{g}}\left(\sigma_{\mathrm{g}}\right)$ for latent orf73 was $0.40(0.11-0.76)$ and did not differ significantly between regions $\left(P_{4 d f}=0.0675\right)$ or education levels $\left(P_{3 d f}=0.0874\right)$. HIV positive women had significantly higher lytic and latent KSHV antibody levels than HIV negative women $\left(\mu_{\mathrm{g}}\left(\sigma_{\mathrm{g}}\right): 1.0(0.50-1.69)\right.$ vs. $0.70(0.28$ $1.27),\left(P_{1 d f}<0.0001\right)$ and $0.54(0.21-0.98)$, vs. 0.36(0.09$0.68)$, respectively) $\left(P_{1 d f}<0.0001\right)$ (Table 1$)$.

\section{Risk Factors for KSHV}

Age, Education and selected characteristics

Seropositivity to KSHV in these women in their reproductive years was not associated with age $\left(P_{\text {trend }}=0.5988\right)$

Table 1 Lytic and latent KSHV antibody levels and Odds Ratios (OR's) for seropositivity by municipal region, HIV and syphilis status and education

\begin{tabular}{|c|c|c|c|c|c|c|c|c|}
\hline & \multirow[b]{2}{*}{$\begin{array}{c}\text { Total } \\
\text { (n) }\end{array}$} & \multirow[b]{2}{*}{$\begin{array}{l}\text { Age Mean } \\
\quad( \pm \text { SD })\end{array}$} & \multicolumn{3}{|c|}{ Lytic K8.1 } & \multicolumn{3}{|c|}{ Latent Orf 73} \\
\hline & & & $\begin{array}{l}\text { Total Positive }(\mathrm{n}) \\
\text { (\% Positive) }\end{array}$ & $\begin{array}{l}\text { Antibody level } \mu \mathrm{g} \\
\text { (SD range) }\end{array}$ & $\begin{array}{c}\text { Adjusted OR } \\
(95 \% \mathrm{Cl})\end{array}$ & $\begin{array}{c}\text { Total } \\
\text { Positive } \\
\text { (n) }\end{array}$ & $\begin{array}{l}\text { Antibody level } \mu \mathrm{g} \\
\quad \text { (SD range)* }\end{array}$ & $\begin{array}{c}\text { Adjusted OR } \\
(95 \% \mathrm{Cl})\end{array}$ \\
\hline All Subjects & 1740 & $26.0(6.2)$ & $568(32.6)$ & $0.77(0.31-1.38)$ & - & $568(32.6)$ & $0.40(0.11-0.76)$ & - \\
\hline \multicolumn{9}{|l|}{$\begin{array}{l}\text { Municipality } \\
\text { Region }\end{array}$} \\
\hline Soweto & 293 & $24.9(5.8)^{\mathrm{ab}}$ & $76(25.9)$ & $0.71(0.27-1.29)^{b}$ & 1 & $79(27.0)$ & $0.37(0.09-0.73)$ & 1 \\
\hline Ekurhuleni & 567 & $26.5(6.3)^{\mathrm{a}}$ & 204(36.0) & $0.79(0.30-1.46)$ & $1.7(1.2-2.3)^{*}$ & 195(34.4) & $0.40(0.11-0.77)$ & $1.5(1.0-2.1)$ \\
\hline Emfuleni & 330 & $25.9(6.3)$ & 107(32.4) & $0.75(0.32-1.32)$ & $1.5(1.0-2.1)^{*}$ & 118(35.8) & $0.40(0.13-0.74)$ & $1.7(1.2-2.4)^{*}$ \\
\hline Tshwane & 207 & $25.8(6.1)$ & $53(25.6)$ & $0.71(0.32-1.21)^{\mathrm{a}}$ & $1.1(0.7-1.7)$ & $52(25.1)$ & $0.36(0.10-0.68)$ & $1.0(0.7-1.6)$ \\
\hline West Rand & 343 & $26.4(6.1)^{\mathrm{b}}$ & $128(37.3)$ & $0.84(0.37-1.49)^{\mathrm{ab}}$ & $1.6(1.1-2.3)^{*}$ & $124(36.2)$ & $0.43(0.13-0.82)$ & $1.5(1.0-2.2) *$ \\
\hline$P_{4 d f}$ & & 0.0063 & & 0.0069 & 0.0233 & & 0.0675 & 0.0185 \\
\hline \multicolumn{9}{|l|}{$\begin{array}{l}\text { Education } \\
\text { Level }\end{array}$} \\
\hline$<2$ years & 117 & $28.5(7.9)^{\mathrm{a}}$ & $46(39.3)$ & $0.90(1.67-0.35)^{a}$ & 1 & $47(40.2)$ & $0.45(0.12-0.90)$ & 1 \\
\hline $2-5$ years & 513 & $26.5(6.8)^{\mathrm{b}}$ & 193(37.6) & $0.82(0.32-1.48)^{b}$ & $0.8(0.5-1.2)$ & $176(34.3)$ & $0.40(0.11-0.85)$ & $0.6(0.4-1.0)$ \\
\hline $6-12$ years & 119 & $26.4(5.6)$ & $35(29.4)$ & $0.75(0.30-1.36)$ & $0.4(0.3-0.8)^{*}$ & $37(31.1)$ & $0.42(0.14-0.80)$ & $0.5(0.3-0.9) *$ \\
\hline Post Matric & 959 & $25.4(5.5)^{\mathrm{ab}}$ & 286(29.8) & $0.73(0.31-1.30)^{\mathrm{ab}}$ & $0.6(0.4-0.8)^{*}$ & $300(31.3)$ & $0.42(0.11-0.72)$ & $0.6(0.4-0.9) *$ \\
\hline$P_{3 d f}$ & & 0.042 & & 0.0019 & 0.002 & & 0.0874 & 0.0426 \\
\hline \multicolumn{9}{|l|}{$\begin{array}{l}\text { HIV } \\
\text { Infection }\end{array}$} \\
\hline Negative & 1338 & $26.2(6.4)$ & $345(25.8)$ & $0.70(0.28-1.27)$ & 1 & $341(25.5)$ & $0.36(0.09-0.68)$ & 1 \\
\hline Positive & 402 & $25.3(5.4)$ & $223(55.5)$ & $1.00(0.50-1.69)$ & $3.7(2.9-4.7) *$ & $227(56.5)$ & $0.54(0.21-0.98)$ & $3.8(3.0-4.8) *$ \\
\hline$P_{1 d f}$ & & 0.011 & & $<0.0001$ & $<0.0001$ & & $<0.0001$ & $<0.0001$ \\
\hline \multicolumn{9}{|l|}{$\begin{array}{l}\text { Syphilis } \\
\text { Infection }\end{array}$} \\
\hline Negative & 1442 & $25.9(6.2)$ & $461(32.0)$ & $0.77(0.31-1.38)$ & 1 & $454(31.5)$ & $0.39(0.10-0.75)$ & 1 \\
\hline Positive & 298 & $26.4(5.8)$ & 107(35.9) & $0.79(0.34-1.38)$ & $1.0(0.7-1.3)$ & 114(38.3) & $0.43(0.15-0.81)$ & $1.2(0.9-1.6)$ \\
\hline$P_{1 d f}$ & & 0.24 & & 0.55 & 0.8924 & & 0.087 & 0.2395 \\
\hline
\end{tabular}

${ }^{\#} \mu \mathrm{g}\left(\mathrm{SD}\right.$ range) geometric mean and standard deviation range. Means with the same letter are significantly different $(p, 0.05) .{ }^{*}$ Statistically significant Odds Ratios. 
(Table 2). While older age appeared to be protective against HIV infection, this relationship was not seen in the adjusted model. An inverse trend for KSHV was noted with higher education levels $\left(P_{\text {trend }}=0.0015\right)$ being protective against KSHV but not HIV infection. More than half (53.0\%) of the 117 women with no formal education $(<2$ years) were seropositive to KSHV decreasing to $41.7 \%$ in the 959 women with the highest high school matriculation certificate $\left(P_{3 d f}=0.008\right)$. The number of pregnancies and live births had no effect on KSHV seropositivity. (Table 2). KSHV, HIV and Syphilis serology

The overall seroprevalence of HIV and syphilis, in pregnant women across all the clinics was $23.1 \%$ and $17.1 \%$, respectively. Overall, $34.6 \%$ of all the women had either HIV or syphilis but only $6 \%$ were infected with both. Seropositivity to KSHV was $69.7 \%$ in HIV infected women and $37.1 \%$ in uninfected women $(\mathrm{p}<0.0001)$ (Table 2). Pregnant women with syphilis also had higher KSHV seroprevalences than those without $(51.7 \%$ vs $43.1 \%$ respectively; $\mathrm{p}=0.0028)$. The prevalence of HIV and syphilis were $12.7 \%$ and $14.9 \%$ in pregnant women without KSHV, and 36.1 and $19.9 \%$ in those with positive KSHV serology. The risk for KSHV was 4.1 fold higher in those with HIV infection (4.1 95\% CI: 3.1 5.2). However, KSHV was not associated with syphilis (AOR 1.2 95\% CI: 0.9 - 1.6) (Table 2). KSHV antibody levels were higher in women with HIV but not in women with syphilis (Table 1)

\section{Geographic factors and KSHV serology}

Seropositivity to KSHV was significantly different amongst the municipal regions, ranging from $35.4 \%$ in Tshwane to $49.0 \%$ in the West Rand $\left(P_{4 d f}=0.0015\right)$ (Table 2). Risks of KSHV infection was higher in all pregnant women attending clinics in Ekurhuleni and Emfuleni and the West Rand regions, compared to women attending clinics in Soweto (AOR 1.8 95\% CI: 1.3 - 2.4; 1.8 95\% CI: 1.1 - 2.6; and $1.795 \% \mathrm{CI}: 1.1$ 2.5) (Table 2). While the risk for KSHV was similar between Soweto and Tshwane, women in the Tshwane region seem to be at a low risk for HIV infection compared to those from Soweto (AOR 0.5 95\%CI: $0.3-0.8$ ) (Table 2).

To further explore this geographic variation in KSHV serology within this region, we looked at the river catchments within the different regions. It was clear that there were two main river catchment systems draining south and north (Figure 1). KSHV seroprevalence was higher in the areas with the southern river drainage (45.6\%) than those to the north $(39.0 \%)$, however this difference was not significant $\left(\mathrm{p}_{1 \mathrm{df}}=0.4\right.$, Table 2$)$.

\section{Discussion}

Although HIV prevalence in South African women attending public sector antenatal clinics is well described [21], little is known about their KSHV status. In the sub-Saharan African setting it is now apparent that KSHV is an endemic infection affecting both children and adults $[10,12,25,26]$ and that HIV is a significant co-factor in the pathogenesis of Kaposi's sarcoma $[2,27,28]$. In addition to studies suggesting sexual transmission of KSHV [26] and among HIV negative individuals [29], other studies on the epidemiology of KSHV from endemic African and Mediterranean countries have also established that the virus is transmitted via non-sexual routes $[9,10,12,30]$. Our findings provide further evidence for non-sexual horizontal transmission of KSHV, likely via saliva. However, risk factors for KSHV infection, the exact mode of KSHV transmission and other epidemiological cofactors that may promote KSHV infection need further elucidation.

In this study, KSHV seroprevalence in pregnant women attending antenatal clinics in the Gauteng province of South Africa was very high (45\%) and nearly double that of HIV infection (23\%). This further confirms that KSHV infection is very common in Southern African women consistent with previous reports where reported prevalence ranged from $30 \%$ - 46\% [6,12,26]. HIV was strongly associated with increased risk for KSHV seropositivity as well as the risk of having both lytic and latent antibodies, as we have previously reported in a study of mothers and children from throughout South Africa [12]. However, we have also previously demonstrated in a mining community (Carletonville) with very high prevalence of both HIV and $\mathrm{KSHV}$, that KSHV was not associated with HIV infection nor was it associated with other sexually transmitted infections [9]. The reasons for this discrepancy is unclear but may relate to the very high HIV prevalence in the Carletonville study population[9]. None of these studies found any association between KSHV infection and other STD including syphilis. In this study HIV positive subjects had significantly higher KSHV antibody levels than their HIV negative counterparts, an association not noted for syphilis. Higher antibody levels in HIV positive subjects may reflect poor immune control of $\mathrm{KSHV}$ resulting in more frequent reactivation.

The lack of association between KSHV and age noted in this study may be attributed to the narrow age range studied (mean ( \pm SD) 25.9 (6.2)). In this study, pregnant women with a higher level of education had lower rates of KSHV infection. The association between KSHV and increasing education has been shown in other studies [29]. Education is often reported to be a surrogate marker of socio-economic status. implying that those with lower socio-economic status are at a higher risk for KSHV infection, consistent with previous reports [18,29]. 
Table 2 Factors affecting the odds ratios (OR) for KSHV and HIV in pregnant women attending antenatal public clinics in Gauteng province of South Africa.

\begin{tabular}{|c|c|c|c|c|c|c|c|}
\hline & \multicolumn{4}{|c|}{ KSHV Seropositivity } & \multicolumn{3}{|c|}{ HIV Seropositivity } \\
\hline & $\begin{array}{c}\text { Total } \\
\text { (n) }\end{array}$ & $\begin{array}{l}\text { Prevalence } \\
\text { Total } n(\%)\end{array}$ & $\begin{array}{l}\text { Unadjusted OR }{ }^{\#} \\
(95 \% \mathrm{Cl})\end{array}$ & $\begin{array}{c}\text { Adjusted OR } \\
(95 \% \mathrm{Cl})\end{array}$ & $\begin{array}{l}\text { Prevalence } \\
\text { Total } n(\%)\end{array}$ & $\begin{array}{c}\text { Unadjusted OR } \\
(95 \% \mathrm{Cl})\end{array}$ & $\begin{array}{c}\text { Adjusted OR } \\
(95 \% \mathrm{Cl})\end{array}$ \\
\hline All Subjects & 1740 & $\begin{array}{c}776 \\
(44.6 \%)\end{array}$ & - & - & $402(23.1 \%)$ & - & - \\
\hline \multicolumn{8}{|l|}{ Age Group } \\
\hline$\leq 20$ & 362 & $154(42.4)$ & 1 & 1 & $87(24.0 \%)$ & 1 & 1 \\
\hline $21-25$ & 533 & $246(46.2)$ & $1.2(0.9-1.5)$ & $1.2(0.9-1.7)$ & $136(25.5 \%)$ & $1.1(0.8-1.5)$ & $1.1(0.7-1.5)$ \\
\hline $26-30$ & 438 & $192(43.8)$ & $1.1(0.8-1.4)$ & $1.1(0.8-1.5)$ & 108(24.7\%) & $1.0(0.7-1.5)$ & $1.0(0.7-1.5)$ \\
\hline$\geq 31$ & 407 & $184(45.2)$ & $1.1(0.8-1.5)$ & $1.2(0.9-1.6)$ & $71(17.4 \%)$ & $0.7(0.4-0.9)^{*}$ & $0.7(0.5-1.0)^{*}$ \\
\hline$P_{3 d f}$ & & & 0.6240 & 0.4830 & & 0.0286 & 0.0373 \\
\hline \multicolumn{8}{|l|}{$\begin{array}{l}\text { Municipality } \\
\text { Region }\end{array}$} \\
\hline Soweto & 293 & 105(35.4) & 1 & 1 & $72(24.6 \%)$ & 1 & 1 \\
\hline Ekurhuleni & 567 & $274(48.3)$ & $1.6(1.3-2.2)^{*}$ & $1.8(1.3-2.4) *$ & $147(25.9 \%)$ & $1.0(0.7-1.5)$ & $1.1(0.7-1.6)$ \\
\hline Emfuleni & 330 & $152(46.1)$ & $1.5(1.1-2.1) *$ & $1.8(1.1-2.6) *$ & 63(19.1\%) & $0.8(0.5-1.1)$ & $0.7(0.5-1.1)$ \\
\hline Tshwane & 207 & $77(37.2)$ & $1.1(0.7-1.5)$ & $1.3(0.5-1.9)$ & $29(14.0 \%)$ & $0.5(0.3-0.8)^{*}$ & $0.5(0.3-0.8)^{*}$ \\
\hline West Rand & 343 & $168(49.0)$ & $1.7(1.2-2.4) *$ & $1.7(1.1-2.5) *$ & $91(22.6 \%)$ & $1.1(0.8-1.6)$ & $1.1(0.7-1.7)$ \\
\hline $\boldsymbol{P}_{4 d f}$ & & & 0.0015 & 0.0095 & & 0.0017 & 0.0013 \\
\hline \multicolumn{8}{|l|}{ Education Level } \\
\hline$<2$ years & 117 & $62(53.0)$ & 1 & 1 & $17(14.5 \%)$ & 1 & 1 \\
\hline 2- 5 years & 513 & $253(49.3)$ & $0.9(0.6-1.3)$ & $0.7(0.5-1.1)$ & $119(23.2 \%)$ & $1.3(0.8-2.1)$ & $1.4(0.8-2.6)$ \\
\hline $6-12$ years & 119 & $51(42.9)$ & $0.7(0.4-1.1)$ & $0.5(0.3-0.8)^{*}$ & $31(26.0 \%)$ & $1.6(0.8-3.1)$ & $1.4(0.7-2.8)$ \\
\hline Post Matric & 959 & $400(41.7)$ & $0.6(0.4-0.9)^{*}$ & $0.5(0.4-0.8)^{*}$ & $228(23.8 \%)$ & $1.4(0.9-2.1)$ & $1.6(0.9-2.8)$ \\
\hline$P_{3 d f}$ & & & 0.0080 & 0.0034 & & 0.1645 & 0.3437 \\
\hline \multicolumn{8}{|l|}{ Gravidity Group } \\
\hline 1 & 631 & $269(42.6)$ & 1 & - & $144(22.8 \%)$ & 1 & - \\
\hline 2 & 481 & $223(46.4)$ & $1.2(0.9-1.5)$ & - & $129(26.8 \%)$ & $1.2(1.0-1.6)^{*}$ & - \\
\hline$\geq 2$ & 532 & $246(46.2)$ & $1.2(0.9-1.5)$ & - & $106(28.0 \%)$ & $0.8(0.6-1.1)$ & - \\
\hline $\boldsymbol{P}_{2 d f}$ & & & 0.2863 & & & 0.0284 & \\
\hline \multicolumn{8}{|l|}{ Parity group } \\
\hline 0 & 649 & $279(43.0)$ & 1 & - & 149(23.0\%) & 1 & - \\
\hline 1 & 487 & $223(45.8)$ & $1.1(0.9-1.5)$ & - & $129(26.5 \%)$ & $1.2(0.9-1.6)$ & - \\
\hline$>2$ & 506 & $235(46.4)$ & $1.2(0.9-1.5)$ & - & $56(20.1 \%)$ & $0.9(0.6-1.1)$ & - \\
\hline $\boldsymbol{P}_{2 d f}$ & & & 0.3594 & & & 0.0263 & \\
\hline \multicolumn{8}{|l|}{ River Catchment } \\
\hline North & 279 & $109(39.1)$ & 1 & - & $48(17.2 \%)$ & 1 & - \\
\hline South & 1461 & $667(45.6)$ & $0.8(0.4-1.5)$ & - & $354(24.2 \%)$ & $0.6(0.4-0.9)^{*}$ & - \\
\hline $\boldsymbol{P}_{1 d f}$ & & & 0.4312 & & & 0.0075 & \\
\hline \multicolumn{8}{|l|}{ Syphilis } \\
\hline Non-reactive & 1440 & $621(43.1)$ & 1 & 1 & $303(21.0 \%)$ & 1 & 1 \\
\hline Reactive & 298 & $154(51.7)$ & $1.4(1.1-1.8)^{*}$ & $1.2(0.9-1.6)$ & $97(32.5 \%)$ & $1.8(1.4-2.4)^{*}$ & $1.9(1.4-2.5)^{*}$ \\
\hline $\boldsymbol{P}_{\text {ldf }}$ & & & 0.0028 & 0.1168 & & $<0.0001$ & $<0.0001$ \\
\hline \multicolumn{8}{|l|}{ HIV infection } \\
\hline Negative & 1338 & $496(37.1)$ & 1 & 1 & & - & - \\
\hline Positive & 402 & $280(69.7)$ & $3.9(3.1-5.0)^{*}$ & $4.1(3.1-5.2)^{*}$ & & - & - \\
\hline$P_{1 d f}$ & & & $<0.0001$ & $<0.0001$ & & & \\
\hline
\end{tabular}

\footnotetext{
\# Adjusted for age group, education levels, municipal region, syphilis seropositivity and/or HIV status. *Statistically significant Odds Ratios.
} 
We observed significant variation in the prevalence of KSHV between the regions within the Gauteng province of South Africa which remained after adjustment for several factors including age, HIV, syphilis status and education (Table 2). This is the first study in subSaharan Africa to demonstrate such geographical variation within a province. In the apartheid era, most South African townships were segregated according to ethnic and, therefore, geographic origin of the residents. It follows that some of this variation may be explained by differences in cultural practices.

Living in close proximity to rivers and streams has previously been associated with increased risk for KSHV [17]. We did not have information on place of residence for the women in our study, only the clinic that they attended. Therefore, we were unable to test this hypothesis. Further studies are warranted to clarify the nature of the geographical variation in KSHV prevalence observed in this study.

Women attending routine ante-natal clinics are frequently used in surveys of HIV prevalence in South Africa and other African countries. Assessing KSHV prevalence in this population therefore allows for valid comparisons between this study and future studies in other parts of South Africa or other African countries. This study adds to findings in South Africa and other African countries [31] which suggest a lack of evidence for sexual transmission of KSHV in heterosexual African populations. Cross-sectional studies of KSHV and other serology, while providing important information on risk factors for KSHV transmission, have limitations. A longitudinal study of KSHV transmission in South Africa is needed as well as studies aiming to identify geographical, cultural and/or lifestyle and environmental factors that may predispose people to KSHV infection.

\begin{abstract}
Acknowledgements
The authors gratefully acknowledge the South African National Department of Health for granting permission to use the stored laboratory samples and collected data. Special thanks to Helen Mathabatha and Lettie Bester for their assistance with sample and data collection. To Lynne McNamara and Dr Jonathan Levin for preparation of data, Dr. Mathew Fox and Burgert Malan (Map Studio, South Africa) for useful discussions. The Map Studio (South Africa) provided and authorised use of the map. B.I. Malope-Kgokong was the recipient of international travel grants from the South African Medical Research Council, the National Cancer Institute, and the Union Internationale Centre Le Cancer (UICC)-International Cancer Technology Transfer Fellowships (Applicant No. 962/2003). Funded in part by the Intramural Program of the National Cancer Institute, National Institutes of Health, Department of Health and Human Services (contract HHSN261200800001E]; South African Medical Research Council; University of the Witwatersrand and National Health Laboratory Service.
\end{abstract}

\section{Author details}

'Clinical HIV Research Unit, Department of Medicine, Faculty of Health Sciences, University of the Witwatersrand, Johannesburg, South Africa. ${ }^{2}$ Viral Oncology Section, AIDS and Cancer Virus Program, SAIC-Frederick, NCIFrederick, Frederick MD, USA. ${ }^{3}$ Cancer Epidemiology Research Group,
National Health Laboratory Services, Johannesburg, South Africa. ${ }^{4}$ Cancer Research Division, Cancer Council New South Wales, Australia.

\section{Authors' contributions}

BIM-K performed the statistical analysis, wrote the first draft of the manuscript and participated in the design of the study, PM and MM supervised the statistical analysis and contributed to the writing of the manuscript, GM performed the KSHV serology, FS conceived the study and with $L S$ and ER, participated in the design of the study, the statistical analysis and contributed to the writing of the manuscript, DW participated in the design of the study, supervised the KSHV serology and contributed to the writing of the manuscript. All authors read and approved the final manuscript.

\section{Competing interests}

The authors declare that they have no competing interests

Received: 28 July 2010 Accepted: 31 August 2010

Published: 31 August 2010

\section{References}

1. Chang Y, et al: Identification of herpesvirus-like DNA sequences in AIDSassociated Kaposi's sarcoma. Science 1994, 266(5192):1865-9.

2. Whitby $\mathrm{D}$, et al: Detection of Kaposi sarcoma associated herpesvirus in peripheral blood of HIV-infected individuals and progression to Kaposi's sarcoma. Lancet 1995, 346(8978):799-802.

3. Cesarman E, et al: Kaposi's sarcoma-associated herpesvirus-like DNA sequences in AIDS- related body-cavity-based lymphomas. N Engl J Med 1995, 332(18):1186-91.

4. Soulier J, et al: Kaposi's sarcoma-associated herpesvirus-like DNA sequences in multicentric Castleman's disease. Blood 1995, 86(4):1276-80.

5. Whitby $D$, et al: Human herpesvirus 8 seroprevalence in blood donors and lymphoma patients from different regions of Italy. J Natl Cancer Inst 1998, 90(5):395-7.

6. Klaskala W, et al: Epidemiological characteristics of human herpesvirus-8 infection in a large population of antenatal women in Zambia. J Med Virol 2005, 75(1):93-100.

7. Hladik W, et al: Kaposi's sarcoma in Uganda: risk factors for human herpesvirus 8 infection among blood donors. J Acquir Immune Defic Syndr 2003, 33(2):206-10

8. Adjei $A A$, et al: Seroprevalence of HHV-8, CMV, and EBV among the general population in Ghana, West Africa. BMC Infect Dis 2008, 8:111.

9. Malope Bl, et al: No evidence of sexual transmission of Kaposi's sarcoma herpes virus in a heterosexual South African population. Aids 2008, 22(4):519-26.

10. Minhas $V$, et al: Early childhood infection by human herpesvirus 8 in Zambia and the role of human immunodeficiency virus type 1 coinfection in a highly endemic area. Am J Epidemiol 2008, 168(3):311-20.

11. Stein $L$, et al: The spectrum of human immunodeficiency virus-associated cancers in a South African black population: results from a case-control study, 1995-2004. Int I Cancer 2008, 122(10):2260-5.

12. Malope $\mathrm{Bl}$, et al: Transmission of Kaposi sarcoma-associated herpesvirus between mothers and children in a South African population. J Acquir Immune Defic Syndr 2007, 44(3):351-5.

13. Crum NF, et al: Correlates of human herpesvirus-8 seropositivity among U.S. military members recently infected with human immunodeficiency virus. Sex Transm Dis 2003, 30(9):713-8.

14. Smith NA, et al: Serologic evidence of human herpesvirus 8 transmission by homosexual but not heterosexual sex. J Infect Dis 1999, 180(3):600-6.

15. Wawer MJ, et al: Prevalence of Kaposi sarcoma-associated herpesvirus compared with selected sexually transmitted diseases in adolescents and young adults in rural Rakai District, Uganda. Sex Transm Dis 2001, 28(2):77-81.

16. de Souza VA, et al: Human herpesvirus-8 infection and oral shedding in Amerindian and non-Amerindian populations in the Brazilian Amazon region. J Infect Dis 2007, 196(6):844-52.

17. Tanzi E, et al: Human herpesvirus type 8 infection in an area of Northern Italy with high incidence of classical Kaposi's sarcoma. J Med Virol 2005, 76(4):571-5. 
18. Mbulaiteye $S M$, et al: Water, socioeconomic factors, and human herpesvirus 8 infection in Ugandan children and their mothers. J Acquir Immune Defic Syndr 2005, 38(4):474-9.

19. Coluzzi M, et al: Saliva and the transmission of human herpesvirus 8: potential role of promoter-arthropod bites. J Infect Dis 2004, 190(1):199-200, author reply 200-1.

20. Whitby D, et al: Reactivation of Kaposi's sarcoma-associated herpesvirus by natural products from Kaposi's sarcoma endemic regions. Int I Cancer 2007, 120(2):321-8.

21. Rice BD, et al: Population and antenatal-based HIV prevalence estimates in a high contracepting female population in rural South Africa. BMC Public Health 2007, 7:160.

22. Shaikh $N$, et al: Masking through averages-intraprovincial heterogeneity in HIV prevalence within the Western Cape. S Afr Med J 2006, 96(6):538-43.

23. Mbisa GL, et al: Detection of antibodies to Kaposi's sarcoma-associated herpesvirus: a new approach using K8.1 ELISA and a newly developed recombinant LANA ELISA. J Immunol Methods 2010, 356(1-2):39-46.

24. de Sanjose $S$, et al: Geographic Variation in the Prevalence of Kaposi Sarcoma-Associated Herpesvirus and Risk Factors for Transmission. J Infect Dis 2009.

25. Mbulaiteye SM, et al: Detection of kaposi sarcoma-associated herpesvirus DNA in saliva and buffy-coat samples from children with sickle cell disease in Uganda. J Infect Dis 2004, 190(8):1382-6.

26. Dedicoat $\mathrm{M}$, et al: Mother-to-child transmission of human herpesvirus-8 in South Africa. J Infect Dis 2004, 190(6):1068-75.

27. Sitas F, et al: The spectrum of HIV-1 related cancers in South Africa. Int J Cancer 2000, 88(3):489-92.

28. Newton $R$, et al: A case-control study of human immunodeficiency virus infection and cancer in adults and children residing in Kampala, Uganda. Int J Cancer 2001, 92(5):622-7.

29. Wojcicki JM, et al: Low socioeconomic status and risk for infection with human herpesvirus 8 among HIV-1 negative, South African black cancer patients. Epidemiol Infect 2004, 132(6):1191-7.

30. Whitby $\mathrm{D}$, et al: Detection of antibodies to human herpesvirus 8 in Italian children: evidence for horizontal transmission. Br J Cancer 2000, 82(3):702-4.

31. Brayfield BP, et al: Postnatal human herpesvirus 8 and human immunodeficiency virus type 1 infection in mothers and infants from Zambia. J Infect Dis 2003, 187(4):559-68.

doi:10.1186/1750-9378-5-14

Cite this article as: Malope-Kgokong et al:: Kaposi's Sarcoma AssociatedHerpes Virus (KSHV) Seroprevalence in Pregnant Women in South Africa. Infectious Agents and Cancer 2010 5:14

\section{Submit your next manuscript to BioMed Central and take full advantage of:}

- Convenient online submission

- Thorough peer review

- No space constraints or color figure charges

- Immediate publication on acceptance

- Inclusion in PubMed, CAS, Scopus and Google Scholar

- Research which is freely available for redistribution

Submit your manuscript at www.biomedcentral.com/submit 